\title{
Objeto, memória e narração no processo de criação de Arthur Bispo do Rosário
}

Object, memory and narration in the creation process of Arthur Bispo do Rosário

\author{
CLÁUDIA MARIA FRANÇA DA SILVA
}

Universidade Federal do Espírito Santo UFES, Vitória, Brasil

\section{RESUMO}

O texto analisa alguns aspectos do processo de criação de Arthur Bispo do Rosário (1909-1989), marcado pelo uso de matrizes objetuais insistentemente envolvidas em fios e tecidos coloridos. Tal como esses objetos, a obra de "Bispo" é envolvida por uma aura composta de elementos místicos, lucidez, delírio e loucura, práticas artesanais tradicionais, memórias de viagem, atenção ao cotidiano, presença da palavra escrita, entre outros aspectos. Agregamos esses aspectos a operações de listagem e catalogação e a conceitos como objeto, coleção, memória e narração.

\section{PALAVRAS-CHAVE}

Arthur Bispo do Rosário, processo de criação, arte objetual, narração.

\begin{abstract}
A B S TR ACT
The text analyzes some aspects of the creation process of Arthur Bispo do Rosário (1909-1989), marked by the use of object matrices insistently involved in colored threads and fabrics. Like these objects, the work of "Bispo" is surrounded by an aura composed of mystical elements, lucidity, delirium and madness, traditional craft practices, travel memories, attention to everyday life, presence of the written word, among other aspects. We add these aspects to listing and cataloging operations and to concepts such as object, collection, memory and narration.
\end{abstract}

\section{KEYWORDS}

Arthur Bispo do Rosário, creation process, object art, narration. 


\section{Considerações iniciais}

Passados mais de trinta anos desde a sua morte e a apresentação de seus trabalhos em importantes exposições artísticas, a riqueza processual da obra de Arthur Bispo do Rosário (Jarapatuba, SE, 1909-1989) ainda nos encanta e surpreende. Grande parte dela se faz pelo uso de "matrizes objetuais" insistentemente envolvidas em fios e tecidos coloridos. De igual maneira, a obra de "Bispo" é envolvida por uma aura de elementos místicos, lucidez, delírio e loucura, práticas artesanais tradicionais, memórias de viagem, atenção ao cotidiano, presença da palavra escrita, entre outros aspectos. Tal complexidade estimula o pensamento sobre o fazer como instância que suplanta o nível dos procedimentos técnicos. Pensamos o processo de criação como movimento não linear no tempo, em que não sabemos precisar a real origem de um trabalho ou mesmo da consciência plena sobre a intencionalidade que marca um projeto poético. Mas ao observarmos diversos trabalhos de um artista, índices diversos revelam-nos sua "inteligência" na agregação e lida com elementos aparentemente inconciliáveis ou díspares, na subversão funcional dos elementos utilizados, no ato interpretativo de seu entorno para uma realidade plástica compossível.

Dentre a fortuna crítica respectiva à obra de Bispo, muito se escreve comparando suas produções a passagens da arte moderna e contemporânea, pela liberdade na pesquisa de suportes, que tem marcado o fazer artístico. No entanto, o percurso desses universos se fez em relativo desconhecimento e silêncio mútuos. Não é nossa intenção discutir se ele foi ou não artista, mesmo porque sua intenção primeira não estava conforme balizas estéticas dominantes; estava imbuído de um dever interno, moral até, de reunir um "universo em miniatura” para apresentar a Deus no dia de seu chamado; um princípio místico consubstanciava o fazer de objetos, bordados e estandartes. Isso não invalida, no entanto, nossas experiências estéticas no contato com sua obra e na atribuição que lhe damos, incontestes: Arthur Bispo do Rosário foi um artista.

Também não é nossa intenção discutir a excentricidade de sua produção, vinculando-a única e exclusivamente à loucura e ao internato em manicômios, alternados nas vivências em casas de seus protetores - embora tenhamos de nos reportar a esse fato, diretamente ligado, como intencionalidade, ao seu fazer.

Desde que vi uma exposição de Arthur Bispo do Rosário no início dos anos 1990 em Belo Horizonte (MG), e mesmo em outros momentos, sempre me chamou a atenção o potencial memorialista de seu trabalho. Como era possível registrar tantas lembranças de histórias vividas e conhecidas, mediante noticiários de jornal, leituras de magazines, conversas e observações do seu entorno, em meio a condições de vida tão turbulentas. Naquele primeiro momento, recém-graduada e inexperiente, veio-me a ideia de que sua arte era o seu modo de contar-nos sua história, envolvente como fazem seus fios coloridos. Um jogo singular do particular com o coletivo. Anos depois, ao conhecer o texto de Walter Benjamin, "O Narrador: considerações sobre a obra de Nikolai Leskov", o trabalho de Arthur Bispo do Rosário me veio imediatamente à mente. Desse modo, o presente texto é memorialista daquela experiência inicial, mas reportando-me também à experiência da leitura do texto do filósofo alemão; desse modo, há aqui uma tentativa de "costurar" reflexões benjaminianas a alguns aspectos do fazer na obra de Arthur Bispo do Rosário. 


\section{Bispo: sua coleção de suportes}

O ex-marinheiro, ex-boxeador, ex-funcionário da Light, ex-auxiliar de serviços domésticos - classificado como "esquizofrênico-paranóide" - tem um surto após uma visão: Deus, rodeado de anjos azuis, dá-lhe a incumbência de reconstruir o Universo ${ }^{1}$. Por conta dessa e de outras crises, Bispo viveu internado por aproximadamente cinquenta anos, principalmente na instituição psiquiátrica Colônia Juliano Moreira (RJ). No entanto, o artífice conseguiu sobreviver a diversos experimentos da medicina psiquiátrica da época, como eletrochoques, cirurgias e medicamentos, apresentando aos médicos comportamentos alternados entre delírios e lucidez; seu comportamento solícito, no entanto, permitia a colaboração frequente nos trabalhos cotidianos da Colônia, bem como na intermediação dos funcionários com outros internos e até mesmo na restauração da ordem na comunidade.

Tal como atelier de artista, seu quarto na Colônia foi palco para a constituição de um imenso arquivo de potências, bem como espaço de trabalho, guarda e visitação de sua obra-vida, lugar para o descanso do corpo e para as alucinações. Nele foram produzidos estandartes bordados, mantos, cetros e outras peças de distinção, objetos "mumificados" (enrolados por fios), assemblages, navios e outras miniaturas. Naquele e em outros espaços, deu vida ao que constituiu o "universo" a ser apresentado a Deus no dia de seu encontro final com a divindade. Afinal, " $a$ ordem recebida por Bispo era irrecusável: inteira a força produtiva do desejo vibrava nele. Um desejo que age como Deus, produzindo multiplicidades" (BURROWES, 1999, p.65).

Para tal, foram coletados e obtidos, tanto por Bispo quanto por outros internos e seus associados (visitantes e funcionários da Colônia), um sem-número de materiais de descarte vestígios, fragmentos e sucatas, com os quais o interno pôde constituir um "acervo" de matérias latentes à espera de ressignificação. Havia uma espécie de "mercado de bens ilícitos" que nutria os desejos dos internos; nele, Bispo "trocava cigarros por frutas ou outro tipo de comida, ou carretéis de linha, doses de pinga por sucata (cabos de vassoura, pregos, papelão, etc.)" (DANTAS, 2009, p. 36). Era comum também o seu passeio pelos confins da Colônia, onde coletava outra sorte de descarte. Sua relação com os outros é desenvolvida por meio de objetos, fragmentos e sucatas. Indo mais além, há muitos momentos em que ele é uma espécie de "firma" (um socius): circulação, beneficiamento e estoque de mercadorias; nesses setores, se percebe uma sociabilidade implícita, seja de objetos entre si, seja dos outros sujeitos fornecedores. Um colecionismo singular é, portanto, a base para a constituição do material a ser trabalhado artesanalmente por Bispo.

Podemos vincular esse aspecto da socialização na construção e manejo de estoque ao pensamento de Abraham Moles (1981) sobre os objetos. Moles define o objeto como "mediador social" e universal: situa-se na relação do indivíduo com seu ambiente mais próximo, com os outros e com ambientes perspectivos e afastados; por meio dos objetos que o indivíduo porta e possui, constroem-se determinados tipos de relações intersubjetivas. Mas o objeto é também considerado

1 Marta Dantas (2009, p.14) escreve: "Quando estava com 29 anos, um acontecimento mudou sua vida: sete anjos the anunciaram que havia sido escolhido por Deus para julgar os bons e os maus e para recriar o mundo para o Dia do Juízo Final - experiência marcante que resultou no diagnóstico de esquizofrenia-paranóide...". 
como um "mediador funcional": prolongamento das ações humanas, o objeto pode ser pensado como prótese que amplia o grau, a duração, a eficiência, a extensão e a intencionalidade dos atos. Desse modo, o objeto insere-se em uma complexa rede de desejos, de sistemas comunicacionais, serviços e signos. A promoção do objeto no cotidiano também torna Bispo um “mediador social”: sujeito que assume uma posição "agenciadora”. Ele tem uma intenção específica e para tal, relaciona-se com vários outros sujeitos fornecedores de “matéria-prima” para a realização de sua finalidade.

Jean-Clarence Lambert (apud MORAIS, 1999, p.226-7) estabelece quatro "métodos" possíveis para se trabalhar o objeto como suporte: “desrealizar", "enigmatizar", "dramatizar" e "acumular/serializar". Tais operações não são excludentes entre si, podendo comparecer indistintamente no fazer. Na desrealização, alija-se o objeto de sua função original e retira-se seu ar de banalidade. Na enigmatização, o objeto nos interroga, gerando leituras não unívocas de sua presença. A dramatização abusa da expressividade da matriz e de seu potencial de nos afetar emocionalmente. E a acumulação/serialização, lida com a quantificação do mesmo objeto ou de semelhanças entre objetos relativamente distintos entre si.

Percebemos a dramatização, por exemplo, nas miniaturas que fazia para as crianças da família Leone ${ }^{2}$, em cuja casa trabalhou como auxiliar de serviços domésticos e para onde voltava sempre que possível, mesmo depois de internado na Colônia Juliano Moreira ${ }^{3}$. A enigmatização poderia apresentar-se, por exemplo, em uma "vitrine" singular, nomeada de "Crânio". Geralmente as vitrines de Bispo são estruturas verticais que suportam conjuntos de objetos semelhantes ou afins, dispostos lado a lado, no preenchimento total do suporte vertical. Desse modo, temos vitrines de canecas, talheres, sapatos, garrafas, chinelos, entre outros. Tais disposições são como apresentações de caixas taxonômicas (como as caixas entomológicas, por exemplo) onde um gênero é explicitado pela apresentação de diversos espécimes de indivíduos; tendemos a ver, na multiplicação da apresentação dos espécimes, as diferenças entre eles. No entanto, em "Crânio", ocorre uma organização que não sabemos distinguir, precisamente, o critério de disposição dos objetos, heteróclitos entre si. Crânio de plástico, paliteiro, um ORFA (Objeto Revestido de Fios Azuis), lápis, um sapatinho de criança e escova de dentes, entre outros fragmentos encontram-se reunidos, representando "pedaços desconexos de um mundo incompreensível, fragmentos de um mundo em ruínas" e nos revelando "a impossibilidade de construção de uma cadeia significativa entre o passado, o presente e o futuro, a impossibilidade da reconstrução de uma realidade". (DANTAS, 2009, p.111)

Embora todas essas operações ou métodos se apresentem nos procedimentos de Bispo para com suas matrizes objetuais, percebemos que a desrealização funcional do objeto é uma tônica,

2 Sugerimos que se veja a imagem do trabalho "Carrossel" em: http://www.google.com.br/imgres?imgurl=https://hoxtonsp.files.wordpress.com/2012/06/bispo-17-carrosel.jpg\&imgrefurl=https://hoxtonsp.wordpress.com/2012/06/29/arthur-bispo-do-rosario/\&h=901\&w=800\&tbnid=iH_6giNioDLwrM:\&zoom=1\&doci$\mathrm{d}=\mathrm{AtT}$ x0_jxbDBmxM\&hl=pt-BR\&ei=dmDOVMnBEs-KNoG-g_AM\&tbm\%20=isch

3 Marta Dantas (2009, p.106-7) comenta: “Que significado podemos atribuir a esse gosto de Bispo pelos brinquedos? Nostalgia de sua infância, prazer pela atividade artesanal? É mais do que isso. O brinquedo recupera algo que ficou perdido na infância, a saber: a superação, segundo Freud, do desprazer e da angústia causados pela ausência da mãe (...). Segundo a teoria freudiana, as crianças reproduzem em seus brinquedos 'tudo o que as impressionou na vida por uma espécie de ab-reação contra a intensidade da impressão que procuram, por assim dizer, dominar."” 
especificamente nos ORFA4 , fios provenientes de uniformes e roupas de cama. Ele desrealiza esses utilitários, comuns a todos os internos, para enigmatizar outros suportes. No câmbio de operações, mantém-se a energia, de certo modo, como no princípio da transferência energética de Lavoisier. Por outro lado, a acumulação e a serialização apresentam-se não somente na fatura dos objetos, mas relacionam-se diretamente à criação e organização de sua coleção.

Para Abraham Moles, colecionar implica constituir uma série mais ou menos infinita "de objetos reunidos para um fim não funcional". A coleção é "caracterizada pela imagem de uma forma (...) imperfeitamente fechada, portanto, aberta ao futuro". (MOLES, 1981, p.138-9). Trabalha-se a partir de um excedente, entre os polos do caos e da ordem; se a missão de Bispo é apresentar o Universo a Deus, é necessário um modo de trabalho que lide com esse movimento pendular entre o caos e a ordem. Umberto Eco (2009) aponta-nos que o imperativo de listar, enumerar e catalogar está sempre presente na história, pois sempre estivemos às voltas com o problema de organizar o excesso de elementos, impondo formas finitas ao inumerável. Afinal, o universo é infinito e passível de se transformar em caos, se não listarmos o que nele vemos. Tais operações seriam estratégias usadas quando "não se sabe quantas são as coisas das quais se fala" ou mesmo "quando não se consegue dar uma definição por essência de uma certa coisa" (ECO, 2009, p.17). São, pois modalidades representativas dessa tentativa de sugestão quase física do infinito. Bispo lida com o excedente também pela listagem e enumeração de nomes próprios, lugares, eventos, partes do corpo, transcrição de textos. Como se passasse em revista diante de tudo o que pudesse ser visto em cada estandarte, vitrine e manto construído. Neste caso

parece paradoxal a ideia de uma lógica cujos termos consistem em sobras e pedaços, vestígios de processos psicológicos e históricos. Mas tudo isso é paradoxal aos nossos olhos, e não sob o ponto de vista da lógica de Bispo, a quem essa organização serviu. (DANTAS, 2009, p.122)

A coleção implica uma estrutura (MOLES, 1981, p.138 et seq) - a série, um socius das coisas, mas também sua instituição, ou seja, a estipulação de normas organizacionais para o conjunto de coisas coletadas. Isso significa dizer que, se por um lado colecionar é agregar, reunir, por outro, a coleção solicita uma atitude de segregação (o arquivamento). Embora o colecionador ame aquilo que é mais do que a soma das suas partes, há um critério interno - "caleidoscópio que realizava arranjos estruturais por meio de restos e cacos" (DANTAS, 2009, p.122) - que seleciona os objetos colecionados do restante dos objetos do mundo. Bispo organiza o que foi listado em conjuntos de "famílias", como está em muitas de suas vitrines.

$\mathrm{O}$ ato de colecionar fragmentos, objetos descartados e sucatas, não é sem sentido; a

4 Sugerimos ver a imagem em: http://www.google.com.br/imgres?imgurl=http://www.rioecultura. com.br/materias/img/110727_arthur_bispo_rosario_02.jpg\&imgrefurl=http://www.rioecultura.com.br/

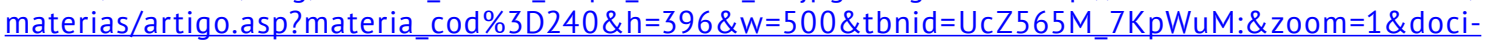
$\mathrm{d}=\mathrm{mn} 5 z z 09 n \mathrm{nT}$ ky7M\&hl=pt-BR\&ei=XmjOVIHsKsHaggTjjoG4BA\&tbm=isch\&ved=0CBsOMygAMAA 
dinâmica da produção industrial equalizou a velocidade da produção de bens ao seu consumo e descarte; o volume de bens culturais já produzidos impõe-nos a apropriação, a citação, o colecionismo, o trabalho da memória. A memória de Bispo espacializa-se nas diferenças entre objetos afins, vestígios de uso, imagens imaginadas e solicitadas pelos textos lidos e bordados, nas combinatórias de cores, linhas, formas e texturas, na maneira de agrupar objetos. De certa maneira, podemos aproximar o quarto-estoque de Bispo - seu depósito de latências - ao lugar ocupado pela memória, o inconsciente tornado lugar.

\section{Bispo: em memória}

Memória é propriedade do ser, atributo sem o qual é impossível criar imagens, nem mesmo imaginar-se criando. Mais que atributo, a memória é uma operação. É possível pensar na memória como operadora consciente na construção de imagens artísticas, mas há também sua involuntariedade: quando um elemento externo qualquer aciona repentinamente um processo intenso de rememoração. Esse encontro fortuito com um elemento externo desloca o sujeito para outra temporalidade, afetando-o intensamente: "Uma porta se abre para a dimensão lateral onde experiências, afetos, paixões, mundos passados e presentes se reúnem vibrando em pura intensidade, ressoando; um tempo fora do tempo, a eternidade da arte”. (BURROWES, 1999, p.63). Memória voluntária e memória involuntária compõem assim o repertório que alimenta e é também alimentado por nossas experiências de tempo e espaço reais. Nosso contato com os fenômenos contribui para o constante trabalho de interpretação e tradução do mundo.

Eclea Bosi (1987) atualiza importante debate sobre modernas concepções de memória, distintas entre si: o conceito de memória de Henri Bergson (em “Matéria e Memória”) e o de Maurice Halbwachs (em “A memória coletiva”).

O objetivo de Bergson é compreender tanto como o passado se conserva e se articula com o presente, quanto os papeis da memória e da percepção neste processo. Uma de suas conclusões é a autonomia do passado em relação ao espírito, pois seu modo de existência é inconsciente. Partindo de uma posição introspectiva, Bergson faz uma importante relação entre percepção e memória. Teríamos a percepção pura dos fenômenos (voltada para ações iminentes, imediatas) e aquela concreta e complexa, a percepção do real imiscuído de lembranças. A memória seria o "lado subjetivo de nosso conhecimento das coisas" (BERGSON apud BOSI, 1987, p. 9), por meio dessas percepções. 0 mundo das lembranças encontra-se latente, em estado potencial no inconsciente e, por isso, caberia à consciência a tarefa de "escolher" e "colher" lembranças, trazendo-as à luz. 0 convívio do consciente com o inconsciente é uma alternância de estados tensos; agimos por meio das "memórias-hábito" (comportamentos automáticos, esforços de atenção e gestos repetitivos) e por meio das imagens-lembrança (ressurreições autênticas do passado, evocações, operantes no sonho e na poesia), de modo conflitivo, em muitas das vezes.

Halbwachs reconhece a existência do caráter "quase onírico" da memória, seu grau de pureza, percebendo que nas imagens do sonho, "o espírito estaria mais afastado da sociedade"; mas igualmente reconhece a impraticabilidade desse estado, considerando que a memória não é apenas sonho, mas trabalho. O trabalho da lembrança reconstrói e recombina experiências 
atuais: é impossível reviver o passado exatamente como foi. Recorremos aos testemunhos para complementar informações que temos sobre um fato. Mas o primeiro testemunho é o nosso. Nossas impressões podem se balizar em nosso próprio testemunho e nas lembranças dos outros sobre o mesmo fato. Deste modo, "nossa confiança na exatidão de nossa recordação será maior, como se uma mesma experiência fosse recomeçada não apenas pela mesma pessoa, mas por muitas" (HALBWACHS, 2006, p. 29). Halbwachs pretende relacionar a memória com a história e com a organização de grupos sociais. Para ele, família, escola, profissão e outros laços intersubjetivos organizam e consubstanciam a memória de um sujeito. O sociólogo não se propõe a pensar nas complicações do processo mnemônico em razão das singularidades de cada indivíduo por seu modo de lembrar como o temperamento, vontade ou personalidade. Caberia à linguagem o papel social mediador das diferenças nos conteúdos sonhados ou lembrados, reduzindo, unificando e aproximando os sujeitos, num “mesmo espaço histórico e cultural”.

Fausto Colombo (1991) e Luís Carlos Fridman (2000) problematizam o estatuto da memória na contemporaneidade, vinculada que está a uma "super-presença" de registros e coisas em nosso entorno, recursos anti-esquecimento. Sabemos da impossibilidade do retorno às experiências totais vividas no passado; o esquecimento é o outro lado da moeda memorialista. Há uma relativização de sua potência porque o retorno à experiência originária é apenas uma promessa. $O$ esquecimento, o silêncio e o silenciamento são agentes que relativizam a lembrança e a narração do lembrado. Confiamos então nos vestígios, registros e espécimes da cultura material com os quais nos cercamos, acreditando que eles poderão reconstituir a suposta unidade de nossa memória e, portanto, de nossa subjetividade. Luís Carlos Fridman aponta o quanto hoje se consome para atingir sensações não experimentadas anteriormente. E se essas sensações são o horizonte para a conquista da "identidade" perdida, tendemos a consumir, acumular e reter, numa promessa de satisfação. Compramos

alimentos, cosméticos, carros, óculos, pacotes de férias, aparelhos de ginástica, (...) na adoção de estilos de vida associados às mercadorias. Para tal, é necessário esquecer para transitar sem embaraços no eterno presente. (FRIDMAN, 2000, p.82).

Percebemos em Bispo entretecidas essas possibilidades de ação da memória: a noção bergsoniana, como evocação pura e imediata e a correspondência entre memória e inconsciente, bem como a noção de trabalho/reconstrução na memória, concebida por Halbwachs. No estranho acesso involuntário ao inconsciente, Bispo pinça momentos de passado, criando imagens-lembrança em lampejos de urgência, de trabalho intenso, de intempestividade no fazer. A intuição lhe acorre indicando o momento preciso para agir. Mas é no trabalho com as matérias que a memória se reconstrói e trabalha a si mesma no lento ato de desfiamento e de enovelamento, como se detivesse, naqueles fios, o peso do tempo. As palavras são escritas, mas do modo mais lento: bordadas. Aqui, não há mais o imediatismo da palavra evocada, mas a lentidão da expressão da palavra que se borda, ou mesmo na reconstrução de objetos por meio do desfiamento e do enovelamento. Pareceme que estas são operações que clamam por uma lentidão temporal, construindo sobre o tecido- 
suporte, outro tecido-texto ${ }^{5}$, outra textura do tempo rememorado: "o ato de escrever bordando parece que organizava os pensamentos do artista ou os arquivos de sua memória" (DANTAS, 2009, p.135). Podemos perceber também que o colecionismo de Bispo é de outra ordem. O horror vacui do qual se cerca e age não diz respeito ao tédio do homem moderno, que não sabe o que fazer com o presente e com a precariedade das suas experiências e memórias. Diferentemente dos que acumulam para fugir de um vazio existencial, parece que as acumulações de Bispo dizem do contrário: há muito que escrever, bordar e organizar, porque há muito do que se lembrar. A memória, em Bispo, parece ser ativada pela presença excessivamente objetual, com a qual constrói sua sociabilidade, e pela designação divina de seu fazer.

\section{Bispo: experiência e narração}

Walter Benjamin legou-nos dois textos sobre o compartilhamento de experiências: “Experiência e Pobreza” ([1933], 1994a) e "O narrador: considerações sobre a obra de Nikolai Leskov" ([1936], 1994b). Embora sejam textos anteriores à Segunda Guerra Mundial, muitas de suas considerações ainda ressoam em nós.

Em ambos os textos, o acento do autor sobre a importância da narração como prática agregadora de pessoas. O filósofo percebe como a modernidade nos trouxe a noção da imediaticidade, que transformou nossa capacidade de compreender, ouvir e narrar estórias. Isto porque a passagem para a modernidade promove uma experiência de "desorientação" do sujeito, fazendo-o questionar vários valores da tradição e mesmo sua condição de ser exemplar para os outros. Também perdemos nossa capacidade de transmitir conhecimento, por conta mesmo do processo de individualização e da substituição do valor “conhecimento" pelo valor “informação”, cujo poder foi instaurado pela derrocada da oralidade.

Walter Benjamin constrói a figura de "O narrador..." pensando no nascimento da subjetividade moderna, vinculando esse nascimento à emergência do romance moderno. A cultura moderna substitui as informações orais por informações escritas e pelo ato solitário de leitura. Com o domínio da imprensa, o livro torna-se o elemento de ligação da solidão do romancista com solidão do leitor. (Ibid, p. 201) Se a narração, presente em culturas não marcadas pelo individualismo, tem como funções a transmissão de experiências, explicação dos fatos com o intuito de preservação de costumes, tradições e ensinamentos, ela estabelece uma relação singular de interação entre o narrador e sua audiência. A presença de vários ouvintes compartilhando uma mesma e única experiência narrada singulariza o relato, por mais distante que esteja no tempo; ele atualiza-se nos ouvintes.

Um narrador é, antes de tudo, um conselheiro. Aconselhar é sugerir a continuação de uma história narrada. Conselho e sabedoria andam juntos, mas a sabedoria está em extinção. Desse modo, a prática de aconselhar e de transmitir ensinamentos vai perdendo força; lugares e situações costumeiros dessas práticas, vão se colocando à margem da vida. Sob o signo da imediaticidade,

5 Sugerimos as imagens do Manto da Apresentação em http://bienal.org.br/post.php?i=351 e http://espacohumus.com/arthur-bispo-rosario/ 
a moderna consciência coletiva tem construído estratégias para resguardar a experiência da morte. Essa mesma consciência segrega e oculta sujeitos e fenômenos, que de algum modo foram convertidos em obstáculos à rotina da vida diária.

Desde aqui já é possível pensar na condição de segregação de Arthur Bispo do Rosário. Anthony Giddens estabelece o termo "arena de segregação" relacionado desde o contexto iluminista, para designar lugares que agregam indivíduos "desviantes” do corpo social, sob o rótulo de "pobres": loucos, velhos, viúvas, órfãos, doentes, deficientes e insanos (GIDDENS, 2001, p. 147). Hospitais e sanatórios, lugares onde ocorre a profissionalização de práticas e saberes médicos e a concentração da tecnologia médica, são também considerados como "arenas de segregação". Em seus interiores constitui-se um mundo híbrido apartado da vida social. Ainda povoam nosso imaginário como lugares de difícil visitação, vinculando-se também à ideia de que ali se mantém o controle dessa população a ser excluída. Se para Benjamin, "Cada manhã recebemos notícias de todo o mundo. E, no entanto, somos pobres em histórias surpreendentes” (BENJAMIN, 1994, p.203), a vida dos internos não se alinha ao universo das informações sucintas e rápidas que recebemos a cada manhã; tais personagens guardam em si uma sabedoria que, pela segregação da rotina diária, fica impedida de ser transmitida àqueles que não são "pacientes". Suas vidas percorrem uma temporalidade singular, em que o ato memorialista e a lentidão são modos impróprios a um viver que, para comprovar sua eficácia, os exclui institucional e socialmente. Marta Dantas (2009, p.107) escreve: "Tal como acontecia com os objetos industriais quando deixavam de cumprir o seu papel, os seres humanos eram descartados, jogados fora como lixo. Bispo fez parte dessa lógica. Era ele, também, colecionador e objeto colecionado."

Benjamin exemplifica a figura do narrador em duas situações: a do viajante/marujo e a do camponês/artesão. Enquanto o viajante percorre espaços, acumulando experiências de viagem, conhecendo novas culturas e introduzindo o dado externo na comunidade que o escuta - quando do retorno da viagem - a figura do camponês mantém tradições, repassando-as. Cada um desses tipos gerou modos diferentes de narração. Entretanto, a extensão real da narração é dada pela interpenetração dos dois modelos. Percebemos que Bispo encarna as duas figuras, simultaneamente. $\mathrm{O}$ chamado divino como eixo deliberativo do fazer soma-se à sua vasta experiência como marinheiro, boxeador, funcionário de empresa e de residência, sua infância em um ambiente onde o bordado e a construção de brinquedos eram práticas comuns - tudo isso the deu vasto repertório a ser lembrado, a ser ressignificado e a ser transmitido. Bispo tinha muito talento na construção de miniaturas e brinquedos, bem como na prática dos bordados. Ainda ocorre de vincularmos os trabalhos domésticos e os bordados ao universo feminino, mas no caso de nosso artífice, eram práticas comuns no Nordeste. Marta Dantas coloca-nos sobre a prática comum em regiões mais pobres do Brasil na construção de brinquedos, em que se verifica a capacidade transformadora dos adultos ao combinarem "técnicas tradicionais com material rudimentar" (DANTAS, 2009, p.106). E quanto aos bordados, Japaratuba, cidade natal de Bispo, ficou famosa por sua tradição nesta artesania; é provável que ele tenha aprendido várias técnicas com as bordadeiras locais, contrariando a tradição de se vincular o bordado a uma prática essencialmente de mulheres (lbid, p.133).

Com relação ao uso da palavra escrita bordada em seus suportes, acreditamos que a 
palavra seja um elemento importante em um tripé em que se ancora a visualidade de seus objetos. Em um vértice temos o fazer artesanal dos objetos; em outro, o modo taxonômico de composição e organização dos elementos assemblados; no terceiro vértice, o uso da palavra. É o agenciamento desses elementos que singulariza, por meio de seus conteúdos e pelo próprio uso da linguagem, a narração em Bispo. $O$ artífice elabora longos textos que combinam a lentidão do bordado ao aspecto convulsivo de seus enunciados, plenos de neologismos, elisões e supressões de letras. Escrevendo sempre em letras de caixa alta, o próprio Bispo nos diz (apud DANTAS, 2009, p.130): "Eu passei com letras maiúsculas pra eu e os outros poder ver. É a minha biografia".

Mesmo que Walter Benjamin situe a decadência da narração na passagem da oralidade para a linguagem escrita e seu modo solitário de recepção, Bispo se serve da leitura solitária dos textos de jornais, guias e revistas, as informações sobre concursos de misses, por exemplo, para a extração de nomes, fatos e descrições, que serão representados em seus objetos. Ele escreve bordando as palavras como se as falasse; seus depoimentos, ao contarem de sua própria vida, contam também de uma determinada época do país e também de eventos mundiais. Isso nos remete ao gênero confessional "memórias", pensadas mais como construção do que como descrição de um sujeito, embora seja importante citar fatos gerais e pessoas envolvidas nesses fatos como um modo de contextualizar a existência subjetiva; desse modo, as memórias aproximam-se das narrativas históricas, já que ambas buscam por uma exemplaridade que se delineia na narração dos fatos de uma comunidade.

Podemos pensar que as narrações de Bispo são "micronarrativas", pois não se referem a grandes feitos épicos, embora ele se considere como um ser especial, por sua função de apresentarse a Deus juntamente com seu universo em miniatura. A modernidade, segundo Verena Alberti (1991, p. 70 et seq), estabelece esse tipo de paradoxo, em que coabitam, nas memórias e outras tipologias autobiográficas, o desejo de auto-diferenciação (a ideia de valor), ao mesmo tempo em que ocorre uma consciência da igualdade, em que se é como qualquer um, e por isso com direitos e deveres iguais. Bispo era capaz de se isolar por várias semanas em seu quarto - a dizer que "estava se transformando" - mas também era capaz de trabalhar, ajudando nas tarefas comuns e cotidianas da Colônia ou mesmo como doméstico na residência da família Leone.

Essa questão problematiza a indicação de Benjamin acerca da exaustão das narrativas modernas pela pobreza de nossas experiências e pela proliferação de práticas privadas; é possível que a narração tenha resistido às transformações profundas advindas dos novos meios de produção, do romance e sua leitura individualizada. Percebemos que o memorialista também difunde e exemplifica a sua experiência, a partir de seu ponto de vista singular, e, nesse sentido, tal qual a "narração" - o autor (in)forma, aconselha e ensina o "ouvinte”. Bispo conseguiu articular aspectos pessoais a fatos exteriores à sua vida, percebendo conexões intrínsecas entre eles, percebendo a trama temporal que se fía ao entendimento de si. Ao materializar (ou enovelar) suas memórias em outra maneira de narrar, ele abriu perspectivas de interação com os outros, nas relações de semelhança e dessemelhança com outras micronarrativas já existentes ou em potência. 


\section{Considerações finais}

Procuramos expor, neste texto, certos aspectos da processualidade criativa de Arthur Bispo do Rosário. A excentricidade de sua vida e a designação de uma missão divina aliaram-se a saberes provenientes de sua vasta experiência de vida. Embora sejam dados importantes, não os colocamos como determinantes na compreensão de sua obra, mas como dados direcionadores na percepção de certas constantes ou padrões. Pensamos que há uma triangulação importante no processo de criação de Bispo, dada desde a matriz objetual (suportes como objetos já fornecidos, objetos construídos), por meio da qual se revela a sua maestria artesanal, o uso das palavras escritas e números como estratégias de narração e contabilização do existente, numa espécie de construção de uma "textura para o mundo", para o seu universo, e por fim o modo como organiza espacialmente seus acervos (o excedente de objetos, fragmentos e vestígios), num misto entre o taxonomista/arquivista e o missionário. Imiscuídas nessa triangulação, temos o trabalho da memória e da narração.

Visitar uma exposição artística de trabalhos de Arthur Bispo do Rosário é percorrer o espaço-tempo de visitação a um sujeito, o "Bispo". Imaginando essa exposição como a tradução possível de seu "encontro" com a divindade: perfilam ali os elementos de seu universo, sua vida toda posta de tal maneira escrita e descrita, enovelada, assemblada, mumificada, desfiada, costurada que dizendo à divindade tudo o que se lembrou e que pôde portar consigo, nos diz também sobre uma sucessão de eventos de uma época, espécie de almanaque que nos informa curiosidades sobre países, receitas de como fazer "coisas" (como fazer um muro, por exemplo), os nomes que começam com a letra A, os órgãos do corpo humano, a estrutura de uma embarcação.

Em toda a obra de Bispo subsiste uma presença que também encontra o seu lento processo de decadência na transformação das forças produtivas, desenvolvida pela modernidade: a mão. 0 trabalho artesanal, em que se sobressaem os gestos e as potencialidades manuais, cede cada vez mais espaço à industrialização, à diminuição da experiência tátil na manipulação de matrizes, à vida mediada por objetos cuja concepção não passou pela mão, embora tenham sido feitos para ela. Bispo aproveitou-se de todo esse manancial de uso e descarte recobrindo e reorganizando-o por meio de suas próprias mãos, auxiliadas em parte por aquelas figuras anônimas que o entregaram, em mãos, objetos de troca e descarte. Benjamin vincula a força e a existência de bons narradores aos trabalhos manuais; cria uma analogia entre a narração e o trabalho da mão. 0 autor percebe que narrar é coordenar a alma e os olhos à gestualidade das mãos, o que se apresenta no trabalho do artesão.

O narrador tem o acervo de toda uma vida - a sua e a vida geral, coletiva - para produzir momentos e transmitir experiências de uma "profundidade quase mística". Tal como o imperativo da memória marcando a nova existência de Funes, o memorioso personagem de Jorge Luís Borges, temos no Bispo pós-incumbência divina de reconstruir o mundo, o misto do artesão, viajante, colecionador, catalogador. Não havia espaço para o vazio no tecido bordado por Bispo; deixar espaços vazios equivaleria ao esquecimento, ao silêncio, à ausência. Já alijado do seio social, é preciso, no entanto, tornar-se presente, existir, subsistir e resistir ao empoeiramento das coisas e dos sujeitos. 


\section{Referências}

ALBERTI, Verena. "Literatura e autobiografia: a questão do sujeito na narrativa". Estudos Históricos, Rio de Janeiro, v.4, n. ${ }^{\circ} 7,1991$. p. 66-81.

BENJAMIN, Walter. ([1933], 1994a). "Experiência e pobreza". In:_-_. Magia e técnica, arte e política: ensaios sobre literatura e história da cultura. São Paulo: Brasiliense, 1994. p. 114-119 (Obras escolhidas: v.1)

. ([1936], 1994b). "O narrador: considerações sobre a obra de Nikolai Leskov". In.:

Magia e técnica, arte e política: ensaios sobre literatura e história da cultura. São Paulo: Brasiliense, 1994. p. 197-221. (Obras escolhidas: v.1)

BOSI, Eclea. Memória e sociedade: lembranças de velhos. São Paulo: T. A. Queiroz, 1987.

BURROWES, Patrícia. O Universo segundo Arthur Bispo do Rosário. Rio de Janeiro: FGV, 1999.

COLOMBO, Fausto. Os arquivos imperfeitos. São Paulo: Editora Perspectiva, 1991.

DANTAS, Marta. Arthur Bispo do Rosário: a poética do delírio. São Paulo: Editora da UNESP, 2009.

ECO, Umberto. A vertigem das listas. Lisboa: Difel, 2009.

FRIDMAN, Luis Carlos. Vertigens pós-modernas: configurações institucionais contemporâneas. Rio de Janeiro: Relume Dumará, 2000.

GIDDENS, Anthony. Modernidade e identidade. Rio de Janeiro: Jorge Zahar, 2002.

HALBWACHS, Maurice. "Memória individual e memória coletiva." In: A memória coletiva. São Paulo: Editora Centauro, 2006.p. 29-70.

MACIEL, Maria Esther. "A memória das coisas: Arthur Bispo do Rosário, Jorge Luís Borges e Peter Greenaway." In. . A memória das coisas: ensaios sobre literatura, cinema e artes plásticas. Rio de Janeiro: Lamparina Editora, 2004.

MOLES, Abraham. Teoria dos objetos. Rio de Janeiro: Tempo Brasileiro, 1981.

MORAIS, Frederico. "O campo tridimensional: esculturas, relevos, objetos e instalações." In: TRIDIMENSIONALIDADE: arte brasileira do século XX. São Paulo: Itaú Cultural, 1999. p.226-247. 
PASSERON, René. "A Poïética em questão". PORTO ARTE, Porto Alegre, UFRGS, v.13, n. 21, maio 2004, p. 9-16.

PASSERON, René. La poiéthique. Paris: Klincksieck, 1975, s.p.

\section{Sobre o(a) autor(a)}

Artista visual. Doutora em Artes pela UNICAMP, mestre em Artes Visuais pela UFRGS, bacharel em Artes Plásticas pela UFMG. Professora na Graduação em Artes Plásticas e Pós-Graduação em Artes pela Universidade Federal do Espírito Santo (UFES). Trabalha com desenho, objetos e instalações, expondo regularmente. Participa de reuniões científicas com produção textual.

Currículo Lattes: http://lattes.cnpq.br/3462886315780014

Recebido em: 15-06-2020 / Aprovado em: 30-06-2020

\section{Como Citar}

França, Cláudia. (2020). Objeto, memória e narração no processo de criação de Arthur Bispo do Rosário. Revista Estado da Arte, Uberlândia. v.1, n.1, p.71-83, jan./jun. 2020. https://doi.org/10.14393/EdA-v1-n1-2020-55627 